ARTICLE OPEN

Check for updates

\title{
Design, performance, and demand for a novel in-line chlorine doser to increase safe water access
}

\author{
Julie E. Powers $\mathbb{D}^{1}$, Cynthia McMurry ${ }^{2}$, Sarah Gannon ${ }^{3}$, Adam Drolet ${ }^{3}$, Jared Oremo ${ }^{4}$, Linden Klein ${ }^{5}$, Yoshika Crider $\mathbb{D}^{2,6}$, \\ Jennifer Davis ${ }^{2}$ and Amy J. Pickering $\mathbb{1 D}^{1,2 凶}$
}

Financially sustainable strategies are needed to increase access to safe drinking water in low-income settings. We designed a novel in-line chlorine doser that employs the Venturi principle to automatically add liquid chlorine at the point of water collection (tap outflows). The Venturi does not require electricity or moving parts, and users do not have to change the way they typically collect water. We field-tested the Venturi and assessed its technical performance and sales viability at water kiosks in Kisumu County, Kenya. We offered kiosk owners 6-month service packages to lease or lease-to-own the device; $27 \%$ of kiosks given a sales pitch committed to a service package. All but one kiosk paid in full during the 6-month service period and more than two-thirds purchased the device with payments totaling $>$ \$250 USD per kiosk. Kiosk customers could choose to purchase chlorinated or unchlorinated water from separate taps; $66 \%$ reported buying chlorinated water. Kiosk taps fitted with the Venturi had detectable free chlorine residual $97.6 \%$ of the time. The technical performance of the Venturi and effective demand from kiosks indicate high potential for the Venturi to increase safe water access in low-income communities.

npj Clean Water (2021)4:4; https://doi.org/10.1038/s41545-020-00091-1

\section{INTRODUCTION}

Despite global progress, 2.1 billion people still lack access to safe water at home ${ }^{1}$. Improved drinking water sources have the potential to provide safe water and include piped water, boreholes or tubewells, protected dug wells, protected springs, and packaged or delivered water ${ }^{1}$. While $89 \%$ of the global population uses at least a basic drinking water service (round trip to collect water from an improved source takes $30 \mathrm{~min}$ or less), only $71 \%$ of the global population uses a source that meets the Sustainable Development Goal (SDG) criteria for safely managed (accessible on premises, water available when needed, free from fecal and priority chemical contamination) ${ }^{1}$. In many places, universal access to safe water is out of reach due to the high cost and lack of available financing to create and support necessary water treatment and distribution infrastructure. In some settings that have centralized treatment, leaking pipes, low water pressure, and intermittent supply contribute to recontamination during distribution ${ }^{2-5}$. Intermittent supply has been associated with increased diarrhea ${ }^{6,7}$ and typhoid fever ${ }^{8}$. Piped and other improved sources do not always deliver water free from contamination ${ }^{1-5,9-11}$; an estimated 1.4 billion people use contaminated water from improved sources ${ }^{1}$.

Point-of-use (POU) treatment has been advocated as an interim solution and has been shown to improve water quality ${ }^{12}$ and reduce diarrheal disease ${ }^{12,13}$. Treatment with chlorine products is very affordable $(0.05$ USD per $1000 \mathrm{~L}$ of water treated with chlorine solution when purchased in bulk in Kenya (Paul Byatta, Evidence Action, personal communication, 2020), and it has the advantage of providing residual protection ${ }^{14,15}$. However, sustained uptake and scale up of POU technologies remain low ${ }^{16-18}$ in part because POU places the burden of treatment on individual households, requiring sustained behavior change. This is especially problematic because POU treatment requires high and consistent compliance in order for potential health benefits to be realized-even small declines in compliance result in large reductions of potential health benefits ${ }^{19,20}$.

Water treatment at community collection points, or point-ofcollection (POC) treatment, could lessen the household-level burden of behavior change when centralized treatment and distribution is not feasible. Since $26 \%$ of the global population relies on water collection off-premises ${ }^{1}$, adding treatment devices at the POC may improve access to water free from contamination without large infrastructure improvements. POC chlorine treatment may be manual or automatic; recent studies have evaluated the efficacy and uptake of both in development and emergency contexts [M. Kremer et al., http://www.poverty-action.org/sites/default/files/ publications/chlorinedispensers.pdf, ${ }^{21-26}$. Manual chlorine dispensers add a set volume of diluted chlorine to collection containers $(20 \mathrm{~L})$ with the turn of a knob [M. Kremer et al., http://www.povertyaction.org/sites/default/files/publications/chlorinedispensers.pdf, ${ }^{22,23}$ ]. When installed at shared water points, the dispensers have the potential to increase adoption through social pressure because the decision to use the dispenser is public [M. Kremer et al., http:// www.poverty-action.org/sites/default/files/publications/chlorinedi spensers.pdf]. However, manual chlorine dispensers still require some behavior change by individual users, and uptake rates can be variable [M. Kremer et al., http://www.poverty-action.org/sites/ default/files/publications/chlorinedispensers.pdf, ${ }^{22,23}$ ].

An advantage of automatic (in-line) chlorinators over manual chlorine dispensers is that individuals seeking drinking water do not have to know how to use the device and do not have to change the way they collect water. In-line chlorinators allow users to collect any volume of chlorinated water; manual chlorine dispensers are designed to treat $20 \mathrm{~L}$ at one time. Currently most available electricity-independent in-line chlorinators use solid chlorine tablets ${ }^{27,28}$. In settings where solid chlorine tablets are not widely available, tablet supply can be a significant barrier to sustained chlorinator use ${ }^{21}$. For this reason, members of our team

\footnotetext{
${ }^{1}$ Tufts University, Medford, MA 02155, USA. ${ }^{2}$ Stanford University, Stanford, CA 94305, USA. ${ }^{3}$ PATH, Seattle, WA 98121, USA. ${ }^{4}$ Safe Water and AIDS Project (SWAP), Kisumu, Kenya. ${ }^{5}$ MSR Global Health, Seattle, WA 98134, USA. ${ }^{6}$ University of California, Berkeley, CA, USA. ${ }^{凶}$ email: pickering@berkeley.edu
} 
designed a low-cost, electricity-independent liquid chlorine (e.g. dilute bleach) doser, drawing on our experiences from two previous pilot studies of liquid chlorine dosers ${ }^{24,25}$. A small randomized controlled trial we conducted in urban Bangladesh compared installation of an early prototype of the device tested in this study at shared handpumps to distribution of chlorine tablets (Aquatabs ${ }^{\circledR}$ ). Drinking water chlorination levels were higher in chlorine doser compounds at the POC compared to the Aquatabs ${ }^{\circledR}$ group, suggesting in-line chlorination requires less intensive promotion for sustainable uptake ${ }^{24}$. Another study in Bangladesh tested the $\mathrm{ZIMBA}^{29}$, an automated batch chlorinator that attaches to handpumps or taps and requires a storage tank for mixing after the chorine dose is added. The ZIMBA dosed consistently at handpumps, but users reported that the device caused longer, inconvenient wait times during water collection 25 .

In this study, we designed a novel in-line chlorine doser (the Stanford-MSR Venturi (Fig. 1)) and field-tested the doser at water kiosks in Kisumu, Kenya from August 2017 to May 2018. A potential drawback of POC treatment is that it relies on organized operation and maintenance at the community level; if this fails, the entire community is left without safe water ${ }^{21}$. For this reason, we piloted a business service model and evaluated effective demand (willingness and ability to pay) for the Venturi among kiosk operators and for the resulting treated water among customers. Many other studies of chlorine dispensers and automatic chlorinators have provided the intervention free of charge [M. Kremer et al., http://www.povertyaction.org/sites/default/files/publications/chlorinedispensers.pdf, ${ }^{22-25}$ ], or rarely collected fees in practice due to resistance to paying for water $^{21}$. Our objectives were to assess: (1) the technical performance of the device, (2) customer demand for chlorinated water, and (3) kiosk owner willingness and ability to pay a monthly fee for the device. The study design provided a unique opportunity to assess customer demand for chlorinated versus unchlorinated water as each kiosk offered customers the choice of purchasing from chlorinated or unchlorinated water taps; previous automatic chlorinator studies have not offered or measured this choice $21,24,25,30$.

\section{RESULTS}

Service package enrollment

Seven of the 26 kiosk owners (27\%) who heard the sales pitch committed to purchasing a service package (Table 1), and field staff installed seven Venturi devices. The four service package options were each chosen by one or two kiosks (Table 2). The water source for Kiosk E was a spring; all other kiosk sources were boreholes. Kiosks were urban, peri-urban, and rural (Table 2).

Follow-up: free chlorine residual

All samples collected from the Venturi devices in the lab $(N=71)$ had detectable free chlorine residual. Free chlorine residual ranged from a minimum of $0.5 \mathrm{mg} / \mathrm{L}$ to a maximum of $3.0 \mathrm{mg} / \mathrm{L}$ across needle valve settings (Supplementary Fig. 1). At the settings selected, free chlorine residual was between 0.91 and $1.48 \mathrm{mg} / \mathrm{L}$ across flow rates of $6-38 \mathrm{~L} / \mathrm{min}$ (Fig. 2).

Of 167 water samples collected from kiosk taps fitted with the Venturi, 163 (97.6\%) had detectable free chlorine residual $(>0.05 \mathrm{mg} / \mathrm{L})$. Free chlorine residual ranged from undetected to a maximum of $1.59 \mathrm{mg} / \mathrm{L}$. One hundred and forty-four samples $(88.0 \%)$ had free chlorine residual $\geq 0.2 \mathrm{mg} / \mathrm{L}$, the $\mathrm{WHO}$ recommended minimum ${ }^{31}$. One hundred and sixty-four samples $(98.2 \%)$ had free chlorine residual $\leq 1.2 \mathrm{mg} / \mathrm{L}$, our maximum threshold based on taste acceptability ${ }^{32}$. The device dosed within a precise range: $144(86.2 \%)$ samples had free chlorine residual $\geq 0.2$ and $\leq 1.2 \mathrm{mg} / \mathrm{L}$. Mean free chlorine residual was $0.55 \mathrm{mg} / \mathrm{L}$ (standard deviation: 0.29). The mean free chlorine residual by month since installation remained between 0.37 and $0.74 \mathrm{mg} / \mathrm{L}$ (Fig. 3). Field staff adjusted the dosing dial on 5 of 167 visits (3.0\%). The device functioned with observed flow rates between 2.2 and $63.2 \mathrm{~L} / \mathrm{min}$.

Dosing performance varied by kiosk (Supplementary Table 1). Three of the four observations with no detectable free chlorine residual were collected at Kiosk $F$ (Supplementary Table 1). The device at Kiosk $\mathrm{F}$ performed well during the first three months of installation: all observations were within the desired $0.2-1.2 \mathrm{mg} / \mathrm{L}$ range. However, persistent non-dosing began after month 3 . Field staff examined the device, observed reddish brown sediment deposits clogging the device, and concluded that these deposits were likely caused by iron in the source water. Field staff attempted to clean/unclog the device on multiple visits. Six months after the original installation, field staff uninstalled the device and installed a new device to resolve this problem. Dosing performance improved after the new device was installed (Fig. 3 and Supplementary Fig. 2).

\section{Follow-up: kiosk payments}

Six of the seven kiosks fulfilled all payments of their service package. All three of the kiosks that selected lease-to-own options (kiosks C, E, and G) paid in full and became owners of the device upon completing the final payments. Three of the four kiosks that selected lease options (A, B, and F) paid in full during the study period; and of these, two decided to also purchase the device after 6 months of use ( $A$ and F). Kiosk $D$ missed three payments and field staff uninstalled the device on 24 January 2018, 4 months after installation. In summary, five of the seven kiosks that had a device installed successfully purchased the device. Payments were frequently late: kiosks only made $60 \%$ of possible payments on time. Four of the five kiosks that successfully purchased a device took slightly longer than 6 months to do so; on average, kiosks took 7.5 months to complete payments.

\section{Follow-up: sales}

Overall, chlorinated water sales made up $19.1 \%$ of total water sales at the enrolled kiosks. Only one kiosk collected more average monthly revenue from chlorinated water sales than they spent on monthly service package payments (Supplementary Table 2); however, five of seven kiosks collected more average monthly revenue from combined chlorinated and unchlorinated water sales than they spent on monthly service package payments (Table 2 and Supplementary Table 2). Monthly payments were higher than average monthly revenue at Kiosk $D$, where the device was uninstalled due to payment default. Total water sales fluctuated during the study period and increased during the period 3-6 months after installation (Fig. 3). Based on a median installation date of September 15, this roughly corresponds with Kenya's hot dry season. Only $69.2 \%$ of weekly observations with available data recorded kiosks opening for all days in the week and $30.8 \%$ reported closing at least one day per week. Total water sales, the percentage of water sales that were chlorinated, and chlorinated and unchlorinated water prices varied by kiosk (Fig. 4). Three kiosks sold chlorinated and unchlorinated water for approximately the same price, and four kiosks charged more for chlorinated water (Fig. 4).

\section{Follow-up: customer surveys}

Customers reported purchasing a mean of $142 \mathrm{~L}$ from the kiosks per day (median: $100 \mathrm{~L}$ ). In total, $94.4 \%$ of customers reported purchasing water from the kiosk at least 2 days per week $(43.7 \%$ of customers reported purchasing water from the kiosk every day, while $50.7 \%$ reported purchasing water 2-6 days per week and $5.6 \%$ reported purchasing water 1 day per week or less). Average customer-reported one-way walk time from home to the kiosk was 9.4 min (median: $7 \mathrm{~min}$ ). Most $(91.6 \%)$ customers reported using additional water sources other than the given kiosk, but 

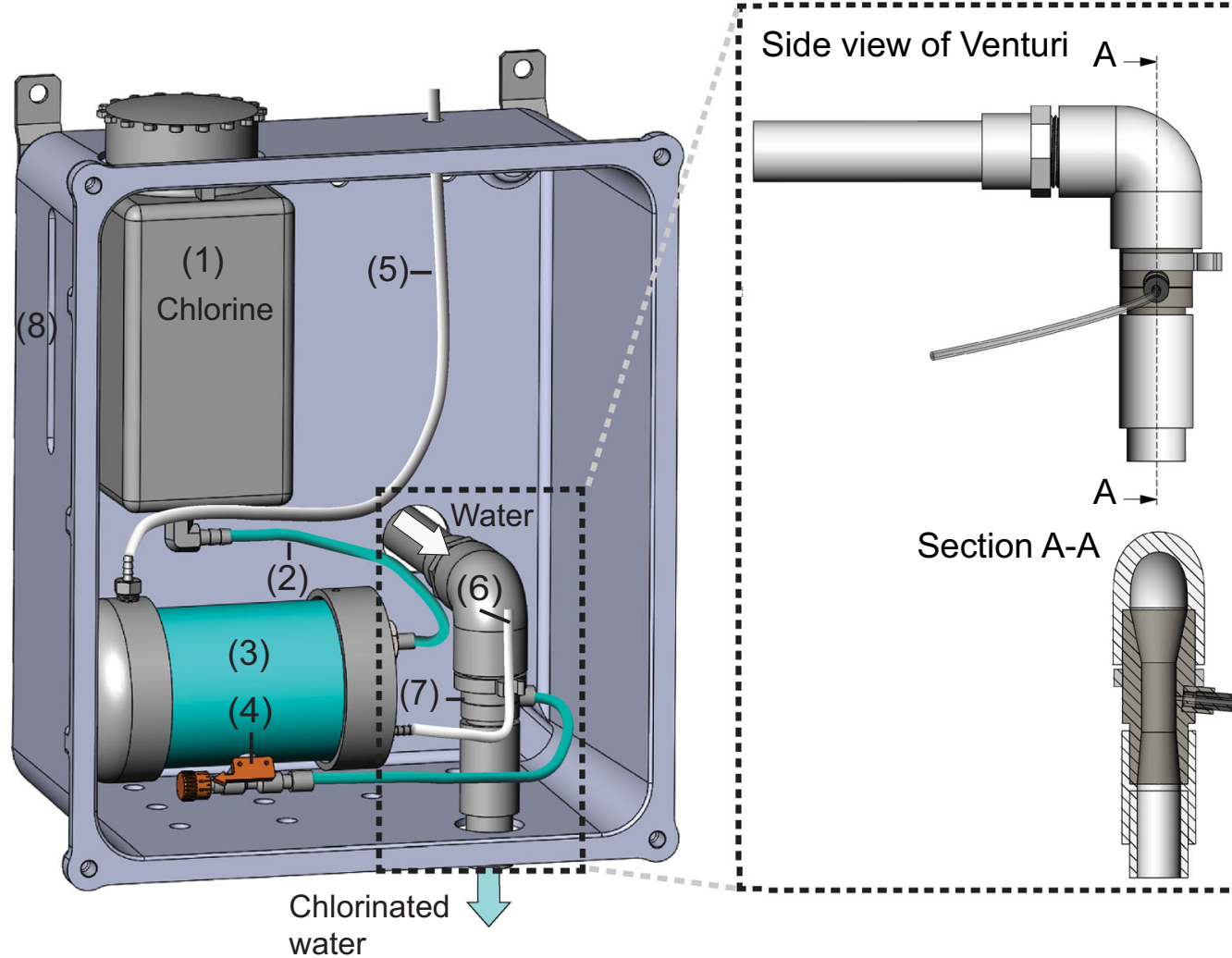

(A)

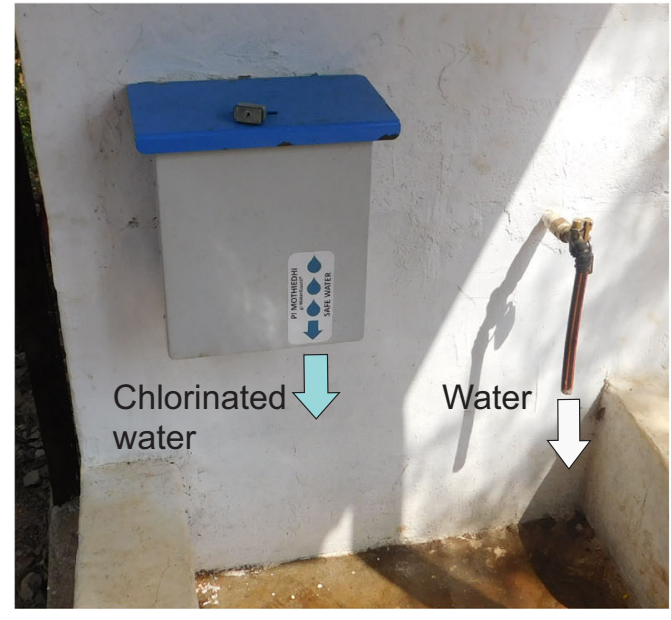

(B)

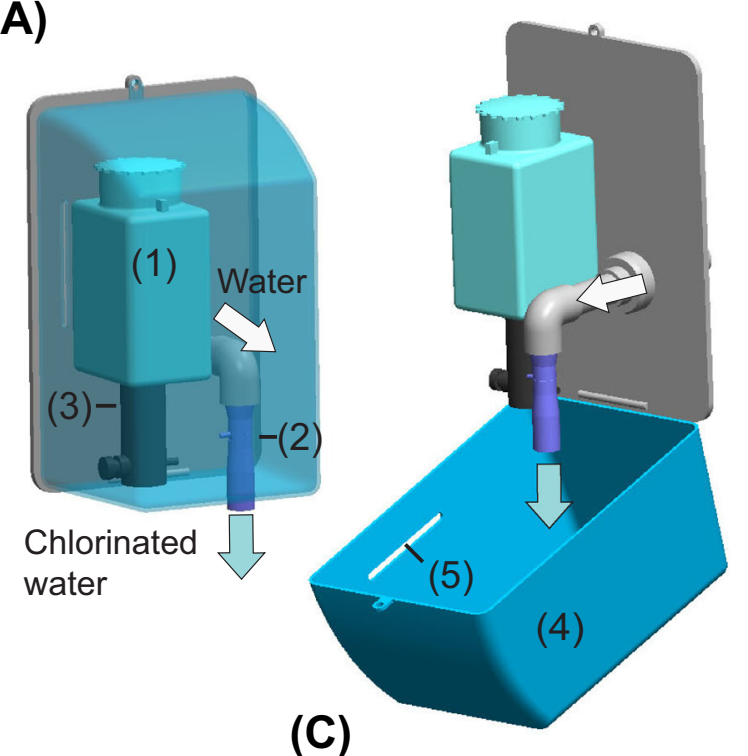

Fig. 1 Novel in-line chlorine doser (Stanford-MSR Venturi). A Schematic cross-section of Venturi. The device consists of (1) 1-L chlorine storage tank; (2) source pinch valve; (3) float tank; (4) needle valve for dose adjustment; (5) vent pinch valve; (6) sight tube; and (7) Venturi. Chlorine flows from the chlorine tank (1) into the float tank (3) when the source pinch valve (2) is open. A float valve maintains the level of chlorine in the float tank. The sight tube (6) may be used to adjust the float tank level to just below the chlorine injection height. The needle valve (4) determines a precise amount of chlorine flowing toward the Venturi (7) and may be adjusted. Differential pressure caused by the flow of water through the Venturi (7) pulls chlorine into the water stream. A window (8) allows operators to easily see the level of chlorine available in the chlorine storage tank. B Venturi installed at water kiosk in Kisumu, Kenya. Left tap provides water chlorinated with the Venturi and right tap provides unchlorinated water. C Concept for future molded Venturi. The device would consist of (1) 1-L chlorine storage tank; (2) molded Venturi; (3) float valve and needle valve assembly; (4) outer cover; and (5) window to see the level of chlorine available. The estimated manufacturing cost of the molded Venturi is 34 USD.

they collected the majority of their water from the kiosk $(66.2 \%$ reported that $>60 \%$ of their household water supply came from the kiosk). Rainwater catchment was the most frequently reported alternative water source: $53.5 \%$ of customers reported practicing rainwater catchment. The high reported use of rainwater is consistent with observed seasonal fluctuation in total kiosk sales (Fig. 3).

Most $(90.1 \%)$ customers reported being very or somewhat satisfied with the quality of water from the kiosks. In total, $52.0 \%$ of customers reported purchasing both unchlorinated water and 
Table 1. Price elements by service package type (in USD).

\begin{tabular}{|c|c|c|c|}
\hline Service package type & Monthly payment & $\begin{array}{l}\text { Lump-sum price for } \\
\text { purchase }^{a}\end{array}$ & $\begin{array}{l}\text { Total price for purchase ( } 6 \text { monthly } \\
\text { payments + lump-sum price) }\end{array}$ \\
\hline Lease & 15 & 170 & 260 \\
\hline Lease-to-own & 42 & & 252 \\
\hline Lease-to-own + chlorine delivery ${ }^{\mathrm{b}}$ & 46 & & 276 \\
\hline
\end{tabular}

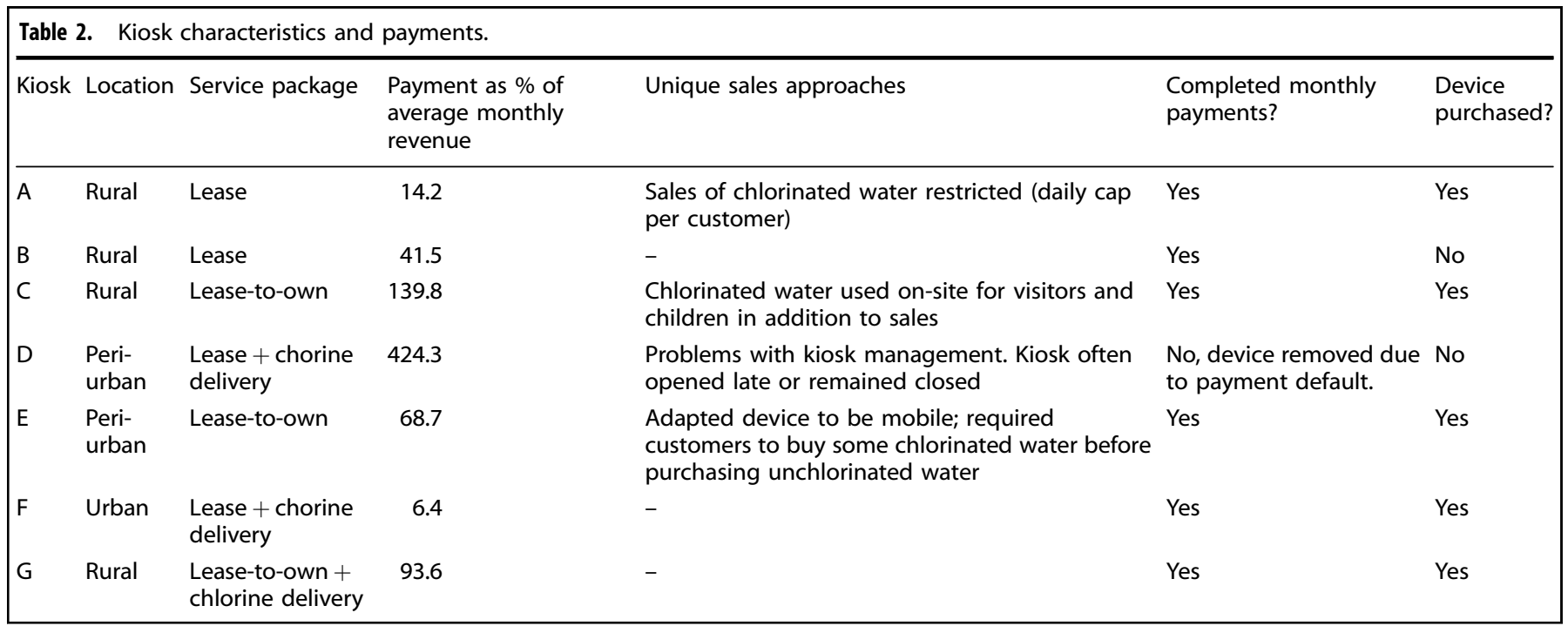

water chlorinated with the Venturi, while $14.1 \%$ reported purchasing only water chlorinated with the Venturi and $33.8 \%$ reported purchasing only unchlorinated water. Water use differed between chlorinated and unchlorinated water: $89.4 \%$ of customers who collected chlorinated water reported using it for drinking, while only $24.6 \%$ of customers who collected unchlorinated water reported using it for drinking. Water safety perceptions also differed between chlorinated and unchlorinated water: $83 \%$ of customers who purchased chlorinated water considered it to be very safe, while only $18 \%$ of customers who purchased unchlorinated water considered it to be very safe. On average, customers reported paying $4.2 \mathrm{KSH}$ (0.042 USD) per 20-L jerry can of chlorinated water and 3.0 KSH (0.03 USD) per 20-L jerry can of unchlorinated water. When asked to list what they liked about the Venturi, attractive/high-quality appearance was the characteristic most frequently mentioned (64.8\% of customers). When asked to list what they disliked, $76.1 \%$ of customers reported that they did not dislike anything about the doser.

Follow-up: operator and manager surveys

All kiosk operators and managers reported satisfaction with the performance of the Venturi and with the quality of water produced by the Venturi. When asked to list what they liked about the Venturi, convenience of use was most frequently mentioned (84.6\% of kiosk operators and managers). When asked for suggestions for how the doser could be improved, the most frequently mentioned suggestion was that the spout should be longer or include an extension pipe $30.8 \%$ of operators and managers). Other suggested improvements included lower price, longer payment periods, ability to serve multiple taps with a single device, improved security, and changes to the appearance. Profits from water sales was most frequently listed as a source of payment for the Venturi (87.5\% of kiosk managers). Other sources of payment included community contributions and donations from partner organizations. Most (75\%) kiosk managers reported that it was somewhat or very difficult for them to make monthly lease payments.

\section{DISCUSSION}

The Venturi consistently chlorinated drinking water at kiosks for 6 months $(97.6 \%$ of all samples had detectable free chlorine residual, with most non-detects from the device with iron deposits) and within a precise range $(86.2 \%$ of samples had free chlorine residual $\geq 0.2$ and $\leq 1.2 \mathrm{mg} / \mathrm{L}$ ). The Venturi performed well in comparison with field trials of other in-line chlorinators, which have reported detectable free chlorine residuals ranging from $77 \%$ to $100 \%^{24,25,30}$ of samples at the POC. Five of the seven devices functioned for 6 months with minimal technical support; one device had to be uninstalled early due to payment default (not technical problems); and one device was replaced after 6 months due to clogging by iron deposits. Overall, the low frequency of technical adjustments to the device $(<5 \%$ of weekly visits) suggests that the device is likely to continue consistent dosing without regular monitoring at kiosks. Notably, our results suggest the device is not suitable for water sources with high levels of iron without a prefilter. Exact iron levels were not measured as part of this study; future work should include measurements of iron 


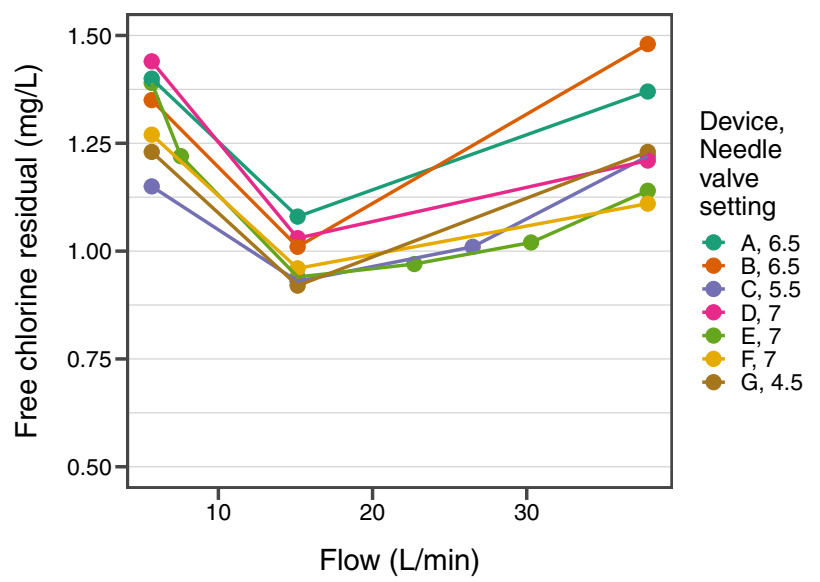

Fig. 2 Free chlorine residual $(\mathrm{mg} / \mathrm{L})$ in water collected from the Venturis in the lab by flow rate $(\mathrm{L} / \mathrm{min})$. The needle valve determines a precise amount of chlorine flowing toward the Venturi and may be adjusted. Needle valve settings correspond to the rotation of the needle valve from closed to open. The settings range from 0 to 10, with 0 representing fully closed and 10 representing fully open. The settings are marked on the needle valve. The needle valve settings shown were selected in the lab and used at installation in the field.

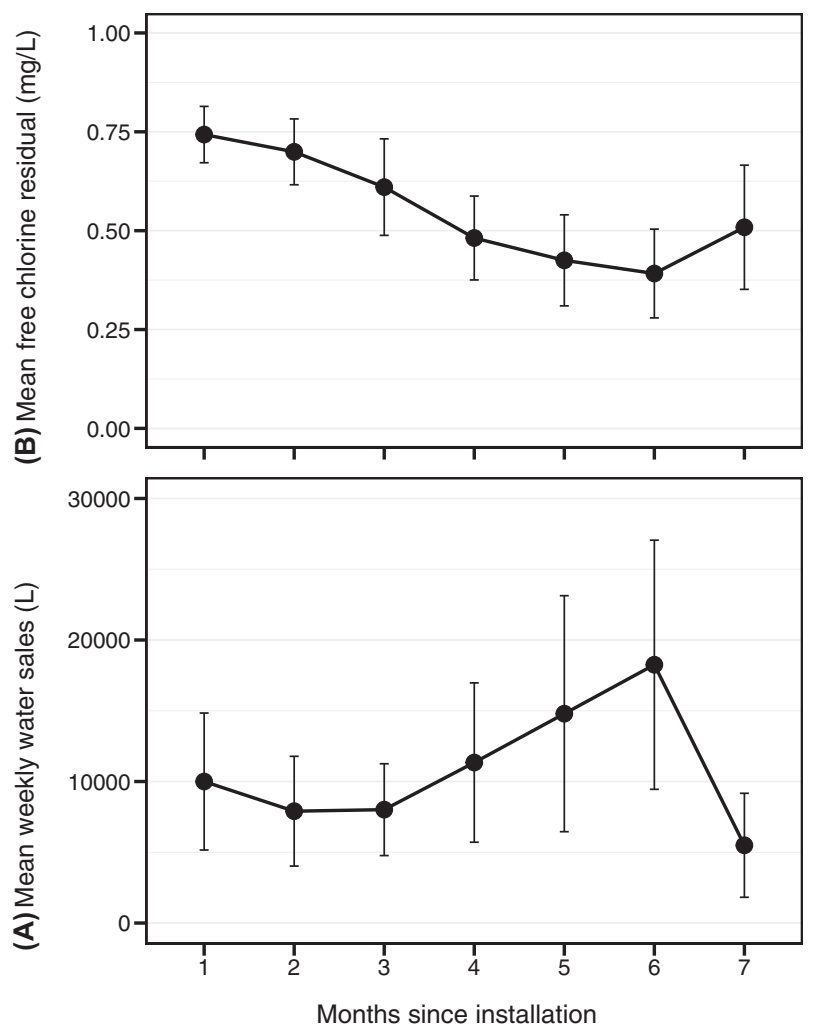

Fig. 3 Water sales (L) and free chlorine residual (mg/L) at all kiosks by month since installation. A Mean weekly water sales (L) at all kiosks by month since installation of the device. B Mean free chlorine residual $(\mathrm{mg} / \mathrm{L})$ in water collected from Venturi at all kiosks by month since installation of the device. Error bars show $95 \%$ confidence intervals. The non-dosing problem at Kiosk $F$ began occurring after 3 months of installation and a new device was installed 6 months after the original installation. Data are aggregated by months since original installation.

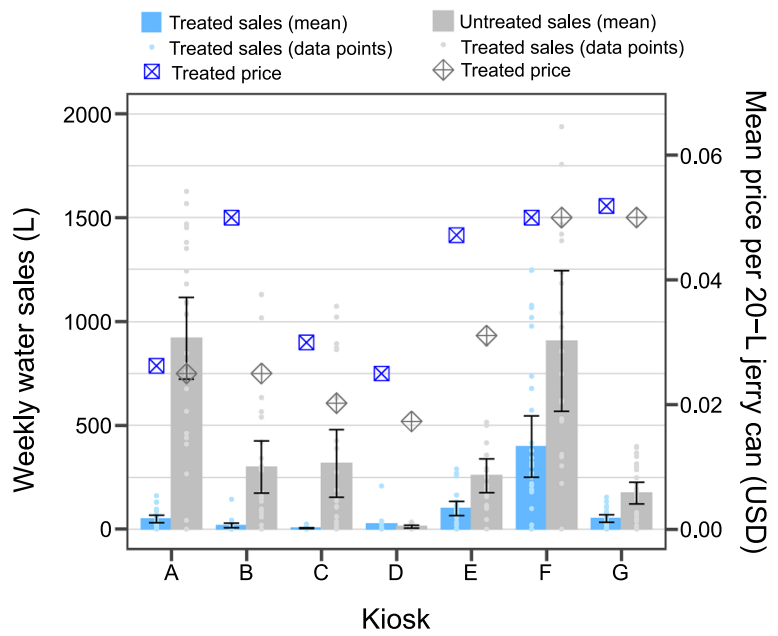

Fig. 4 Weekly water sales (L) and prices (USD) by kiosk. Error bars show $95 \%$ confidence intervals. For weekly water sales data points, outliers $>2000 \mathrm{~L}$ are not shown.

concentration in order to determine if water points should be screened for a threshold concentration of iron prior to installation.

The kiosks' overall success in completing service package payments and in purchasing the devices suggest this technology and the associated service/lease options is a financially viable strategy for kiosks to provide safe water in similar communities. Five of the seven kiosks who committed to a sales package decided to purchase the device after 6 months of device usage experience, suggesting that the device functions well and is desirable to kiosk managers and operators. Effective demand (defined as the ability and willingness to pay) suggested the service package pricing was acceptable. However, only $27 \%$ of kiosks who heard sales pitches committed to a sales package, indicating that kiosks may have self-selected based on ability to pay. Some kiosks reported funding payments solely through water sales, while others subsidized leasing the device through grants and other funding mechanisms. The Venturi may have the potential to scale in the private sector or through subsidies from community organizations, non-governmental organizations (NGOs), and government funding mechanisms. The health benefits of drinking chlorinated water ${ }^{12,13,30,33,34}$ may be viewed as justification for these subsidies, which could enable community access to safe water when effective demand is inadequate for full cost recovery.

Late payments were problematic throughout the study and most kiosks took slightly longer than 6 months to complete purchase payments (7.5 months on average). Several managers of kiosks selecting lease-only expressed a desire to continue making monthly payments rather than a lump sum payment to complete the purchase process. Allowing kiosks to switch from lease to lease-to-own plans or offering only lease-to-own plans with longer payment periods (and lower monthly payments) could enable more kiosks to purchase the device. For example, kiosks could be offered the choice of $6,12,18$, and 24-month lease-to-own payment periods. A payment plan that allows flexibility by season (higher rate during dry season and lower rate during wet season) could also improve payment compliance rates.

Kiosk managers had varying priorities (in addition to maximizing chlorinated water sales), which likely motivated their choice of strategies and contributed to differential sales success between kiosks. Kiosk A typically sold chlorinated and unchlorinated water at the same price, but restricted sales of chlorinated water for drinking use only (using a daily cap per customer) in order to save money on chlorine refills. Chlorinated water sales at kiosk A were 
low (4.4\% of total sales), but this may be due in part to the limit per customer. Since restricting a product can sometimes make it seem more valuable and increase customers' likelihood of purchase ${ }^{35}$, a purchasing limit per customer could lead to a higher proportion of customers purchasing chlorinated water. Keeping the price of chlorinated water similar to unchlorinated water could enable more customers to purchase at least some chlorinated water for drinking purposes. Kiosk B adopted a very different strategy, selling chlorinated water at double the price of unchlorinated water, which resulted in a low volume of chlorinated water sales (5.5\% of total sales) but at a higher price. Comprehensive customer-level sales data (how many customers purchased chlorinated water versus unchlorinated water each week and how much they purchased) was outside of the scope of this study, but would be necessary to test if a higher proportion of customers were purchasing chlorinated water at kiosk $A$ compared to kiosk B. Sales at kiosk C were similarly low $(4.2 \%$ of total sales). However, kiosk $C$ also provided chlorinated water onsite to visitors and children attending feeding programs at the community organization. Thus, the sales data may not fully capture the reach of chlorinated water at kiosk $\mathrm{C}$.

Among kiosks with a higher proportion of chlorinated water sales, some kiosks sold chlorinated and unchlorinated water for the same price or utilized other unique strategies to facilitate the sale of chlorinated water. Kiosk E adapted the device to be mobile and moved it between three different sales sites, responding to demand. Kiosk $\mathrm{E}$ also required customers to buy some chlorinated water before purchasing unchlorinated water. As a result, chlorinated water sales made up a large portion of total water sales (27.4\%) despite its higher price. Kiosks F and $G$ both sold chlorinated and unchlorinated water at approximately the same price and actively promoted the use of chlorinated water for all purposes, and chlorinated water sales made up a large portion of total water sales $(31.7 \%$ and $20.0 \%$, respectively). Chlorinated water sales at kiosk $D$ represented a large portion of total water sales $(52.5 \%)$, but the overall water sale volume was very low. The kiosk often closed, citing competition from nearby KIWASCO water and problems with kiosk management as the reasons for closures.

Since kiosks frequently closed and sometimes forgot to record sales, these results may slightly underestimate total kiosk sale potential if kiosks were open every day. The six-month study period is also a limitation, which did not allow us to fully capture the seasonal effect on water sales throughout an entire calendar year. It is unknown how the device performs long term (beyond 6 months) and without free technical support. It is possible that problems with iron deposits will occur at other kiosks after a longer period of use. Microbial water quality measurements and health outcomes were not included in the study; however, substantial reductions in Escherichia coli ${ }^{24,30}$ and child diarrhea ${ }^{30}$ have been demonstrated by in-line chlorination at similar dosing levels in Bangladesh. Future work examining the effect of in-line chlorination on diarrhea, enteric infections, and under-five child mortality in Sub-Saharan Africa would be valuable for catalyzing investment in scaling up this technology. We were not able to evaluate whether this business model would be profitable for the service provider since Safe Water and Aids Project (SWAP), a local NGO, was providing the service as well as performing research evaluation activities. In practice, the service provider would not need to visit kiosks on a weekly basis, which would significantly reduce staffing and transportation costs. Future work should evaluate whether this model is profitable for a real-world distributor.

The Venturi has several advantages over existing technologies. The estimated manufacturing cost of the molded Venturi (Fig. 1c) is 34 USD with a projected lifespan of 5 years. The device can dose within a precise and acceptable range. Independence from electricity is advantageous, allowing for reliable dosing during power cuts. The device uses WaterGuard (distributed by Population Services International in over 20 countries) or dilute bleach, which are widely available in low-resource settings. Using liquid chlorine is an advantage over solid tablet dosers with cartridges, which require waiting for an empty cartridge and possible non-dosing before replacement. Liquid chlorine has the potential to be more affordable than solid chlorine tablets if produced locally, such as with electrochlorinators ${ }^{27}$. Unlike other product options ${ }^{25,29}$, the Venturi does not affect water collection time. The technical performance of the Venturi, advantages over existing technologies, and effective demand from kiosks suggest that the Venturi has the potential to increase safe water access in low-income communities.

\section{METHODS}

\section{Technology}

The novel Stanford-MSR Venturi (Fig. 1) is an automatic (in-line) chlorinator that can be attached directly to the outlet of piped water taps and is compatible with flow rates of 6-60 L/min. Stanford University researchers and students invented the initial Venturi prototype through a field-based user-centered design process in Bangladesh and Kenya, and the company MSR Global Health refined the design to improve dosing precision and manufacturability. The main challenge of the design process was consistently achieving accurate $( \pm 0.5 \mathrm{mg} / \mathrm{L})$ dosing over a wide range of flow rates with low backpressure and minimal maintenance. Using a test stand in the lab, we optimized the Venturi geometry. Key design parameters of the Venturi are the throat diameter $(\varnothing 12.7 \mathrm{~mm}$, controls the backpressure and range of flow rates the Venturi can accurately dose), the height of the outlet relative to the injection point $(63.5 \mathrm{~mm}$, increases dosing at low flow rates), and the height of the float tank relative to the injection point $(2.0 \mathrm{~mm}$, can cause a dosing delay if too low and affects overall concentration). Since the device operates on very low pressure, a float (constant head) tank is required to prevent the liquid level from affecting the dosing. We selected a needle valve flow restrictor because it dosed more consistently over a range of flow rates and had a wider adjustability range than other flow regulators.

We conducted field tests of early prototypes of the Venturi with user input, which revealed dosing consistency issues that we addressed in the final design. We observed non-dosing at flow rates less than $10 \mathrm{~L} / \mathrm{min}$, caused by channel flow. We mitigated this by making the flow area above the Venturi consistent and minimizing the vertical drop to the injection point. After implementing these changes, we achieved a minimum functional flow rate of below $6 \mathrm{~L} / \mathrm{min}$. Bubbles also formed in the chlorine supply tubing, which was problematic because it could airlock the needle valve or fittings and prevent dosing. We addressed this issue by positioning the needle valve directly on the bottom of the float tank, using compression fittings instead of hose barbs, switching from PVC to fluorocarbon tubing, and eliminating service loops in the tubing. Based on user feedback, we added a security cover to the enclosure to prevent theft of chlorine.

The Venturi can be adjusted to varying doses by twisting a needle valve. Needle valve settings correspond to the rotation of the needle valve from closed to open and range from 0 to 10 , with zero representing fully closed and ten representing fully open. We calibrated the dosing for each Venturi in the lab over a range of flow rates and needle valve settings prior to field installation. We filled each chlorine tank with $1.2 \%$ chlorine solution and allowed dechlorinated water to flow through the Venturi for 30-60 s before collecting a sample of chlorinated water. We measured flow rate using a Dwyer Instruments VFC II and immediately measured free chlorine residual using a Hach Pocket Colorimeter II. For each Venturi, we selected a needle valve setting for installation that resulted in $0.5-1.5 \mathrm{mg} / \mathrm{L}$ free chlorine residual over flow rates of $6-38 \mathrm{~L} / \mathrm{min}$.

The device doses WaterGuard or an equivalent liquid chlorine $(1.2 \%$ sodium hypochlorite) solution, which are readily available in Kenyan markets. Operators may monitor the current level of liquid chlorine in the device through a window on the side of the device (Fig. 1). To refill the device, operators open the cover, remove the cap from the chlorine storage tank, and pour bottles of WaterGuard (or other chlorine solution) directly into the tank. To improve consumer acceptance, we targeted dosing in the field to be between 0.2 and $1.2 \mathrm{mg} / \mathrm{L}$ to avoid high doses that could result in user taste complaints ${ }^{32}$, while still meeting the minimum WHO recommended free chlorine residual ${ }^{31}$.

\section{Study recruitment}

This study was conducted in rural and peri-urban areas of Kisumu, Kenya. In Kenya, water kiosks are common ${ }^{36}$ and typically include multiple taps 
where customers may collect water for a fee per 20-L jerry can. The Safe Water and AIDS Project (SWAP) performed the field activities in this study. SWAP acted as a distributor of the device in some ways (performing sales pitches, installations, and collecting payments). SWAP also performed additional tasks specific to the research study (weekly monitoring and follow-up survey collection). Kiosks were invited to participate in this study if they met the following eligibility criteria: (1) they were located within Kisumu County; (2) they reported operating daily; (3) the water provided was not currently chlorinated (kiosks served by Kisumu Water \& Sewerage Company (KIWASCO) were excluded because the water was reported to be chlorinated); and (4) the kiosk taps were high enough to allow $20 \mathrm{~L}$ jerrycans to pass underneath the outlet fitted with the Venturi ( $\geq$ approximately $65 \mathrm{~cm}$ )

\section{Ethics}

SWAP field staff obtained written informed consent from kiosk owners and operators prior to enrollment in the study. Field staff read consent forms aloud to respondents in Luo, Swahili, or English based on respondent preference. The Ethics Review Committee at Maseno University, Kenya, and the Institutional Review Board at Stanford University (protocol 40689) approved the study protocol.

\section{Baseline}

SWAP field staff conducted baseline surveys with kiosk managers and operators to obtain information on water sales and management practices. Field staff used SurveyCTO software installed on tablet computers to administer these surveys and for all other field data collection.

\section{Intervention delivery}

Following the baseline survey, kiosk owners received a sales pitch and a choice of four service packages (Table 1). All service packages included installation of the chlorine doser and basic maintenance support for up to 6 months. Kiosk owners could decide whether to lease the device or lease-toown the device and whether to have chlorine refills delivered. Kiosks that chose to lease the device had the option to purchase the device for a lump sum at the end of the 6-month study period. At the time of the study, MSR estimated the target sale price of the device to be 150 USD. We therefore developed the service package prices $(6$-month totals, including the lump sum to purchase, ranged from USD 252 to 270) in consultation with project partners in an effort to cover the target sale price of the device, as well as the estimated cost of maintenance and chlorine deliveries.

Since a limited number of Venturi devices (eight) were available for sale, field staff recruited kiosks for sales pitches on an ongoing basis. Kiosk owners made payments via M-PESA, a mobile phone-based money transfer service. Field staff installed the device within 7 days of first payment and provided padlocks to the kiosk operator for securing the device. To install the Venturi, SWAP field staff mounted the rectangular enclosure to the kiosk so that the device fit onto the water supply tap. If necessary, field staff adjusted the diameter of the water supply pipe inlet to connect to the Venturi.

\section{Follow-up}

SWAP field staff made weekly visits to each kiosk. During each visit, field staff conducted a short interview with the kiosk operator to record chlorinated and unchlorinated water sales information for each day of the previous week (usually obtained from a logbook), chlorinated and unchlorinated water sale prices, satisfaction with the device, and any maintenance issues. The volume of sales was self-reported by operators (not verified by meter). Upon arrival, field staff collected three water samples from the Venturi outlet in $250-\mathrm{mL}$ breakers and immediately measured free chlorine residual from each sample using a Hach Pocket Colorimeter $^{\mathrm{TM}}$ |I (https://www.hach.com/pocket-colorimeter-ii-chlorine-freeand-total/product-details?id=7640442953). If free chlorine residual was outside of or close to the limits of our target dose (0.2-1.2 mg/L), field staff repeated sample collection and free chlorine residual measurements. Staff adjusted the dosing dial at their discretion, generally if free chlorine residual was outside or close to the limits of our target dose $(0.2-1.2 \mathrm{mg} / \mathrm{L})$ after repeat testing. If staff adjusted the dosing dial or performed other maintenance, they recorded these changes and collected three additional water samples and free chlorine measurements. Field staff also reminded kiosk operators and managers of upcoming payment due dates and any late payments.
Field staff conducted post-intervention customer surveys between 3 and 6 months after installation, including questions about water purchase behavior, perceptions, and preferences. Field staff surveyed at least 10 customers per kiosk over 2-6 days. Field staff conducted post-intervention kiosk operator and manager surveys between 2 and 5 months after installation, including questions about sales, device perceptions and feedback, and payments.

\section{Data analysis}

We used the mean of the first three free chlorine residual measurements for each visit in our analysis. We considered a detectable level of chlorine residual to be greater than $0.05 \mathrm{mg} / \mathrm{L}$ (based on a colorimeter detection range of $0.02-2.00 \mathrm{mg} / \mathrm{L}$ and incremental steps of 0.01 (ref. $\left.{ }^{34}\right)$ ). Since kiosks opted in on different dates, we aggregated and analyzed dosing and sales data by months since installation, not calendar months. Although operating daily was used in selection criteria, in practice kiosks frequently closed for a variety of reasons such as heavy rain, problems with kiosk management, and political violence related to elections. Because kiosks may have closed in anticipation of low sales, we considered all reported sales and did not adjust based on whether the kiosk had closed (i.e., sales that were missing or the kiosk was closed were counted as zero). We performed data analysis in Stata/SE 14 and created figures in R.

\section{DATA AVAILABILITY}

The data that support the findings of this study are available from the corresponding author upon request.

Received: 24 June 2020; Accepted: 4 November 2020; Published online: 14 January 2021

\section{REFERENCES}

1. World Health Organization (WHO) \& United Nations Children's Fund (UNICEF). Progress on Drinking Water, Sanitation, and Hygiene: 2017 Update and SDG Baselines. http://www.who.int/mediacentre/news/releases/2017/launch-version-report-jmpwater-sanitation-hygiene.pdf (2017).

2. Elala, D., Labhasetwar, P. \& Tyrrel, S. F. Deterioration in water quality from supply chain to household and appropriate storage in the context of intermittent water supplies. Water Sci. Technol. Water Supply 11, 400-408 (2011).

3. Kumpel, E. \& Nelson, K. L. Intermittent water supply: prevalence, practice, and microbial water quality. Environ. Sci. Technol. 50, 542-553 (2016).

4. Kumpel, E. \& Nelson, K. L. Mechanisms affecting water quality in an intermittent piped water supply. Environ. Sci. Technol. 48, 2766-2775 (2014).

5. Kumpel, E. \& Nelson, K. L. Comparing microbial water quality in an intermittent and continuous piped water supply. Water Res. 47, 5176-5188 (2013).

6. Cifuentes, E., Suárez, L., Solano, M. \& Santos, R. Diarrheal diseases in children from a water reclamation site in Mexico city. Environ. Health Perspect. 110, A619-624 (2002).

7. Abu Mourad, T. A. Palestinian refugee conditions associated with intestinal parasites and diarrhoea: Nuseirat refugee camp as a case study. Public Health 118, 131-142 (2004).

8. Ercumen, A. et al. Upgrading a piped water supply from intermittent to continuous delivery and association with waterborne illness: a matched cohort study in urban India. PLoS Med. 12, e1001892 (2015).

9. Heitzinger, K. et al. "Improved" but not necessarily safe: an assessment of fecal contamination of household drinking water in rural Peru. Am. J. Trop. Med. Hyg. 93, 501-508 (2015).

10. Onda, K., LoBuglio, J. \& Bartram, J. Global access to safe water: accounting for water quality and the resulting impact on MDG progress. Int. J. Environ. Res. Public Health 9, 880-894 (2012).

11. Shaheed, A. et al. Water quality risks of 'improved' water sources: evidence from Cambodia. Trop. Med. Int. Health 19, 186-194 (2014).

12. Arnold, B. F. \& Colford, J. M. Treating water with chlorine at point-of-use to improve water quality and reduce child diarrhea in developing countries: a systematic review and meta-analysis. Am. J. Trop. Med. Hyg. 76, 354-364 (2007).

13. Clasen, T. F. et al. in Cochrane Database of Systematic Reviews (ed. The Cochrane Collaboration) (John Wiley \& Sons, Ltd, 2015).

14. Snead, M. C., Olivieri, V. P., Kawata, K. \& Krusé, C. W. The effectiveness of chlorine residuals in inactivation of bacteria and viruses introduced by post-treatment contamination. Water Res. 14, 403-408 (1980).

15. Haas, C. N. Benefits of using a disinfectant residual. J. AWWA 91, 65-69 (1999). 
16. Luby, S. P., Mendoza, C., Keswick, B. H., Chiller, T. M. \& Hoekstra, R. M. Difficulties in bringing point-of-use water treatment to scale in rural Guatemala. Am. J. Trop. Med. Hyg. 78, 382-387 (2008).

17. Luoto, J. et al. What point-of-use water treatment products do consumers use? Evidence from a randomized controlled trial among the urban poor in Bangladesh. PLoS ONE 6, e26132 (2011).

18. Schmidt, W.-P. \& Cairncross, S. Household water treatment in poor populations: is there enough evidence for scaling up now? Environ. Sci. Technol. 43, 986-992 (2009).

19. Brown, J. \& Clasen, T. High adherence is necessary to realize health gains from water quality interventions. PLOS ONE 7, e36735 (2012).

20. Enger, K. S., Nelson, K. L., Rose, J. B. \& Eisenberg, J. N. S. The joint effects of efficacy and compliance: a study of household water treatment effectiveness against childhood diarrhea. Water Res. 47, 1181-1190 (2013).

21. Rayner, J., Yates, T., Joseph, M. \& Lantagne, D. Sustained effectiveness of automatic chlorinators installed in community-scale water distribution systems during an emergency recovery project in Haiti. J. Water Sanit. Hyg. Dev. 6, 602-612 (2016).

22. Null, C. et al. Effects of water quality, sanitation, handwashing, and nutritional interventions on diarrhoea and child growth in rural Kenya: a cluster-randomised controlled trial. Lancet Glob. Health 6, e316-e329 (2018).

23. Yates, T. M., Armitage, E., Lehmann, L. V., Branz, A. J. \& Lantagne, D. S. Effectiveness of chlorine dispensers in emergencies: case study results from Haiti, Sierra Leone, Democratic Republic of Congo, and Senegal. Environ. Sci. Technol. 49, 5115-5122 (2015).

24. Pickering, A. J. et al. Differences in field effectiveness and adoption between a novel automated chlorination system and household manual chlorination of drinking water in Dhaka, Bangladesh: a randomized controlled trial. PLOS ONE 10, e0118397 (2015).

25. Amin, N. et al. Field trial of an automated batch chlorinator system at shared water points in an urban community of Dhaka, Bangladesh. J. Water Sanit. Hyg. Dev. 6, 32-41 (2016)

26. Orner, K. D., Calvo, A., Zhang, J. \& Mihelcic, J. R. Effectiveness of in-line chlorination in a developing world gravity-flow water supply. Waterlines 36, 167-182 (2017).

27. Medentech. Aquatabs Flo. http://www.aquatabs.com/home/product-range/aqua tabs-flo/ (2019).

28. Water Mission. Potable Water Chlorinator. https://watermission.org/wp-content/ uploads/2017/01/PotableChlorinator_Flyer.pdf.

29. Zimba Water. Safe Drinking Water for All. http://zimbawater.com/ (2016).

30. Pickering, A. J. et al. Effect of in-line drinking water chlorination the point of collection on child diarrhoea in urban Bangladesh: a double-blind, clusterrandomised controlled trial. Lancet Glob. Health 7, e1247-e1256 (2019).

31. WHO. Guidelines for Drinking-Water Quality (World Health Organization, 2011).

32. Crider, Y. et al. Can you taste it? Taste detection and acceptability thresholds for chlorine residual in drinking water in Dhaka, Bangladesh. Sci. Total Environ. 613-614, 840-846 (2018).

33. Cutler, D. \& Miller, G. The role of public health improvements in health advances: the twentieth-century United States. Demography 42, 1-22 (2005).

34. Centers for Disease Control (CDC). Safe Water System: Chlorination. https://www. cdc.gov/safewater/chlorination.html (2014).

35. Inman, J. J., Peter, A. C. \& Raghubir, P. Framing the deal: the role of restrictions in accentuating deal value. J. Consum. Res. 24, 68-79 (1997).

36. Wagah, G. G., Onyango, G. M. \& Kibwage, J. K. Accessibility of water services in Kisumu municipality. Kenya J. Geogr. Reg. Plan. 3, 114-125 (2010).

\section{ACKNOWLEDGEMENTS}

We thank SWAP, particularly Pamela Mola and Oscar Akello. Keegan Cooke, Frederick Goddard, Syed Anjerul Mim, Phil Salazar, Kevin Rand, Ellen Ferriss, and Adrian Berg contributed to the design of the Venturi. Funding was provided by the Woods Institute for the Environment and Stanford Institute for Innovation in Developing Economies. The funding organizations had no involvement in study design; in the collection, analysis, and interpretation of data; in the writing of the report; and in the decision to submit the article for publication.

\section{AUTHOR CONTRIBUTIONS}

A.J.P. and J.D. conceptualized and obtained funding for the work. Y.C., L.K., J.D., and A.J.P. contributed to the design of the Venturi. J.E.P., C.M., S.G., A.D., J.O., L.K., J.D., and A.J.P. designed the surveys, service packages, and sales materials. J.O. managed the field work. J.E.P., C.M., S.G., A.D., L.K., J.D., and A.J.P. contributed to project oversight and data review. J.E.P. performed data cleaning and analysis. J.E.P. and A.J.P. wrote the manuscript. All authors reviewed and contributed to the final manuscript.

\section{COMPETING INTERESTS}

L.K. was an employee of MSR Global Health during the study and contributed to the product design in that role; he is no longer employed by the company. No authors have a financial interest in the Venturi doser.

\section{ADDITIONAL INFORMATION}

Supplementary information is available for this paper at https://doi.org/10.1038/ s41545-020-00091-1.

Correspondence and requests for materials should be addressed to A.J.P.

Reprints and permission information is available at http://www.nature.com/ reprints

Publisher's note Springer Nature remains neutral with regard to jurisdictional claims in published maps and institutional affiliations.

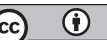

Open Access This article is licensed under a Creative Commons Attribution 4.0 International License, which permits use, sharing, adaptation, distribution and reproduction in any medium or format, as long as you give appropriate credit to the original author(s) and the source, provide a link to the Creative Commons license, and indicate if changes were made. The images or other third party material in this article are included in the article's Creative Commons license, unless indicated otherwise in a credit line to the material. If material is not included in the article's Creative Commons license and your intended use is not permitted by statutory regulation or exceeds the permitted use, you will need to obtain permission directly from the copyright holder. To view a copy of this license, visit http://creativecommons. org/licenses/by/4.0/.

(c) The Author(s) 2021 